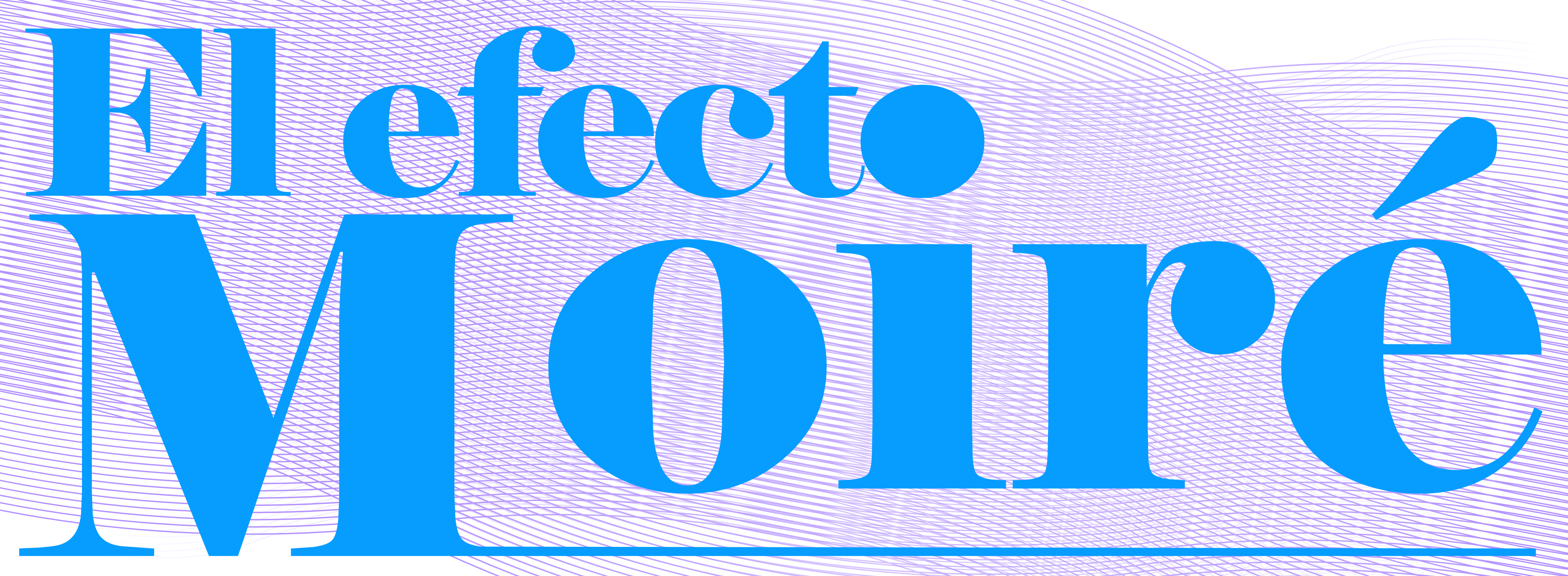




\section{El efecto Moiré}

¿Has observado que, a través de un enrejado metálico, de la baranda de seguridad de un puente o incluso sobre una prenda de vestir de rayas finas, aparecen ciertas figuras que no tienen relación directa con lo que estás observando?

Aquello se conoce como efecto Moiré y corresponde a un fenómeno físico de la óptica lineal, especificamente tiene que ver con la interferencia producida por dos patrones o sistemas que permiten pasar la luz y que poseen una estructura repetida de similares dimensiones.

La interferencia se conoce como el proceso de sumar o restar ondas que se propagan en un medio. Como la luz tiene un comportamiento dual, es decir, onda-partícula, también obedece a la fisica de las ondas $y$, por ende, se interfiere de manera constructiva y destructiva.

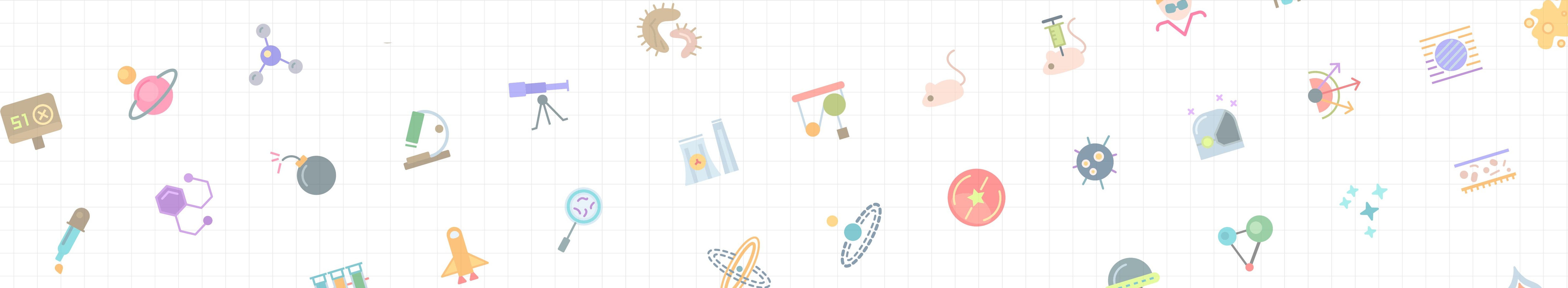


Este efecto no solo es observable a través de la luz visible, sino que también suele aparecer en haces de luces de distinta naturaleza, como, por ejemplo, la luz ultravioleta, los rayos $X$ y el haz de electrones. Este último es la fuente de luz que usa la microscopía electrónica y genera patrones de interferencia que pueden confundirse con los reticulados de ordenamiento atómico.

Una entretenida aplicación del efecto de Moiré es que, a partir de dos imágenes estáticas, es posible generar un efecto dinámico que hace que percibamos una imagen «en movimiento».

En las siguientes láminas podrás ver animaciones de algunos fenómenos científicos que están basados en este interesante efecto.

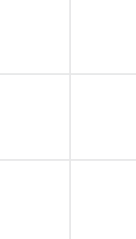




\section{Instrucciones}

Imprime cada una de las ilustraciones que posee este documento en una hoja de papel blanco.

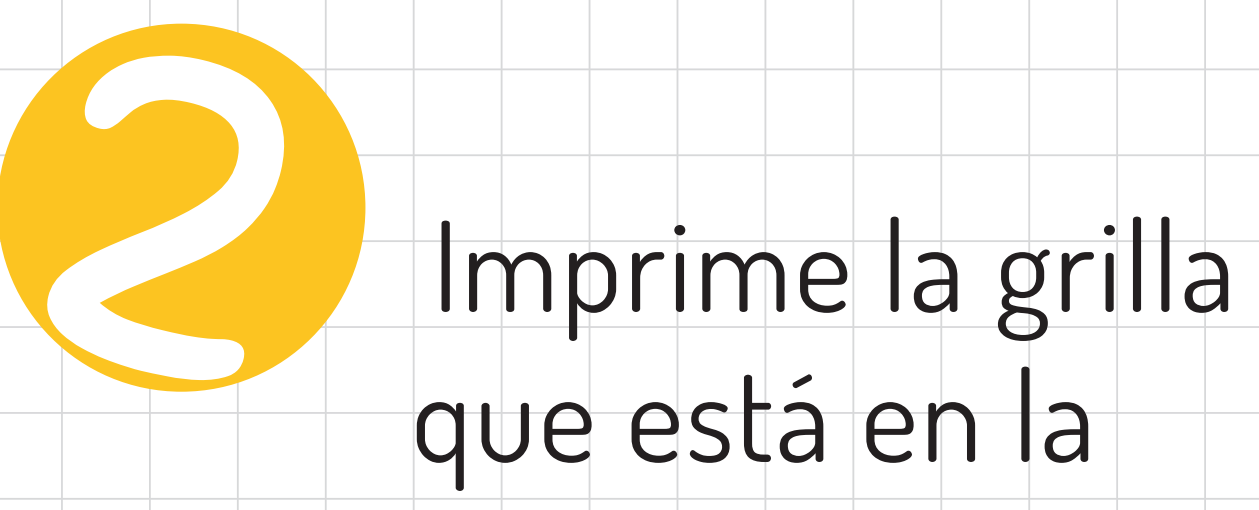
penúltima lámina de este documento en un papel transparente.
Desliza la grilla lentamente, de lado a lado, sobre las animaciones impresas. ¿Qué puedes observar?

IMPORTANTE: para ver el efecto animado no debes cambiar la resolución de las imágenes ni la de la grilla. 


\section{Vibración molecular}

La molécula de agua posee tres tipos de vibraciones, una donde aumenta y disminuye el ángulo formado por los átomos $\mathrm{H}-\mathrm{O}-\mathrm{H}$ y otras dos donde los enlaces $\mathrm{H}-\mathrm{O}$ pueden aumentar o disminuir su longitud. Dado que pueden hacerlo alternada o simultáneamente se producen dos vibraciones distintas, una simétrica y otra antisimétrica.

¿Puedes descubrir cuál es cuál? 

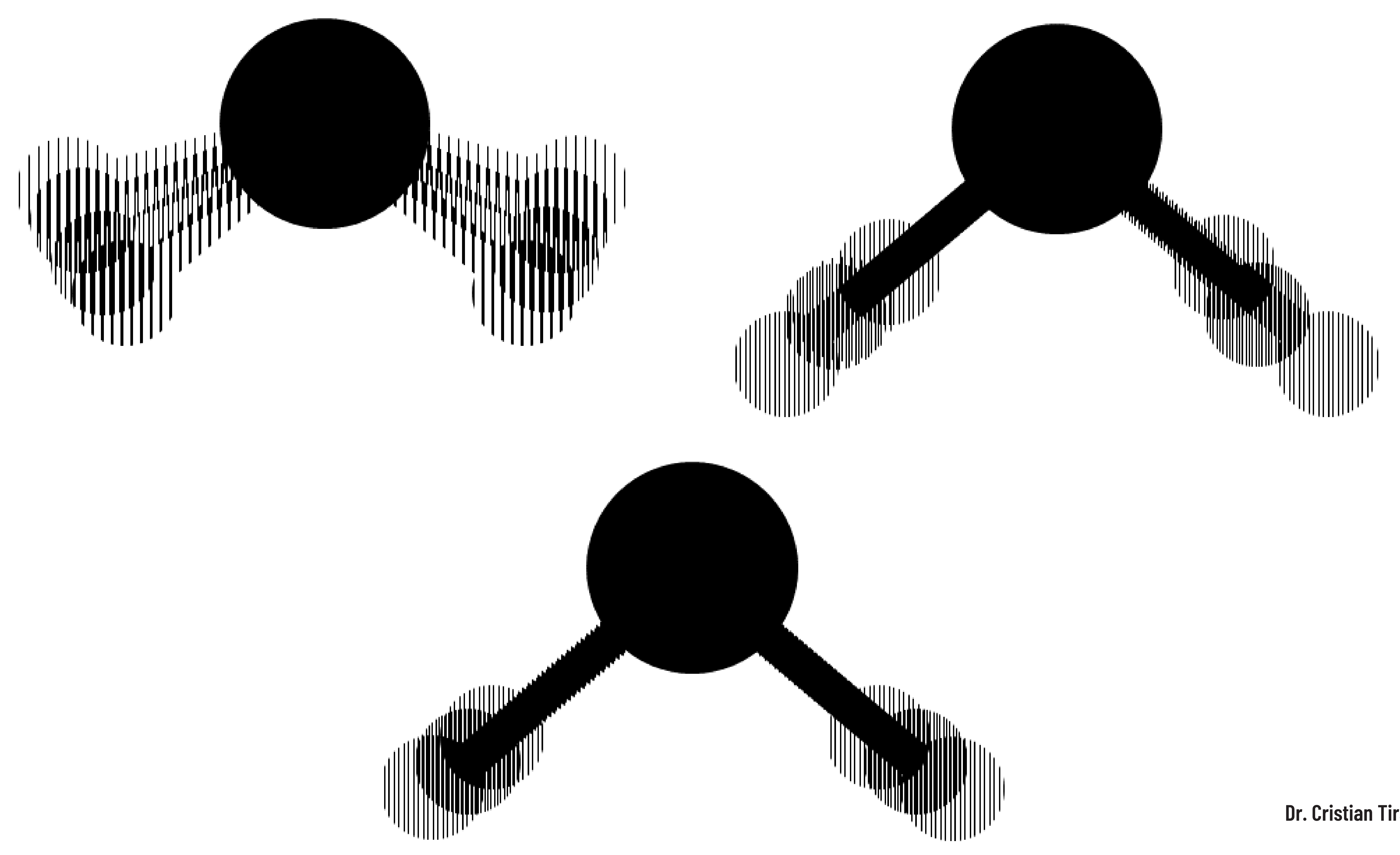

Dr. Cristian Tira 


\section{Estructura resonante y deslocalización electrónica}

Algunas moléculas poseen la capacidad de movilizar ciertos electrones a través de los átomos que conforman su estructura, a esta propiedad se la conoce como deslocalización electrónica, dado que estos electrones pueden poblar distintas regiones de una misma molécula según el grado de deslocalización, a la representación "promedio» de dichas distribuciones se la conoce como estructura resonante.

Observemos, entonces, qué sucede cuando los electrones de los dobles enlaces se deslocalizan en la molécula del benceno. 


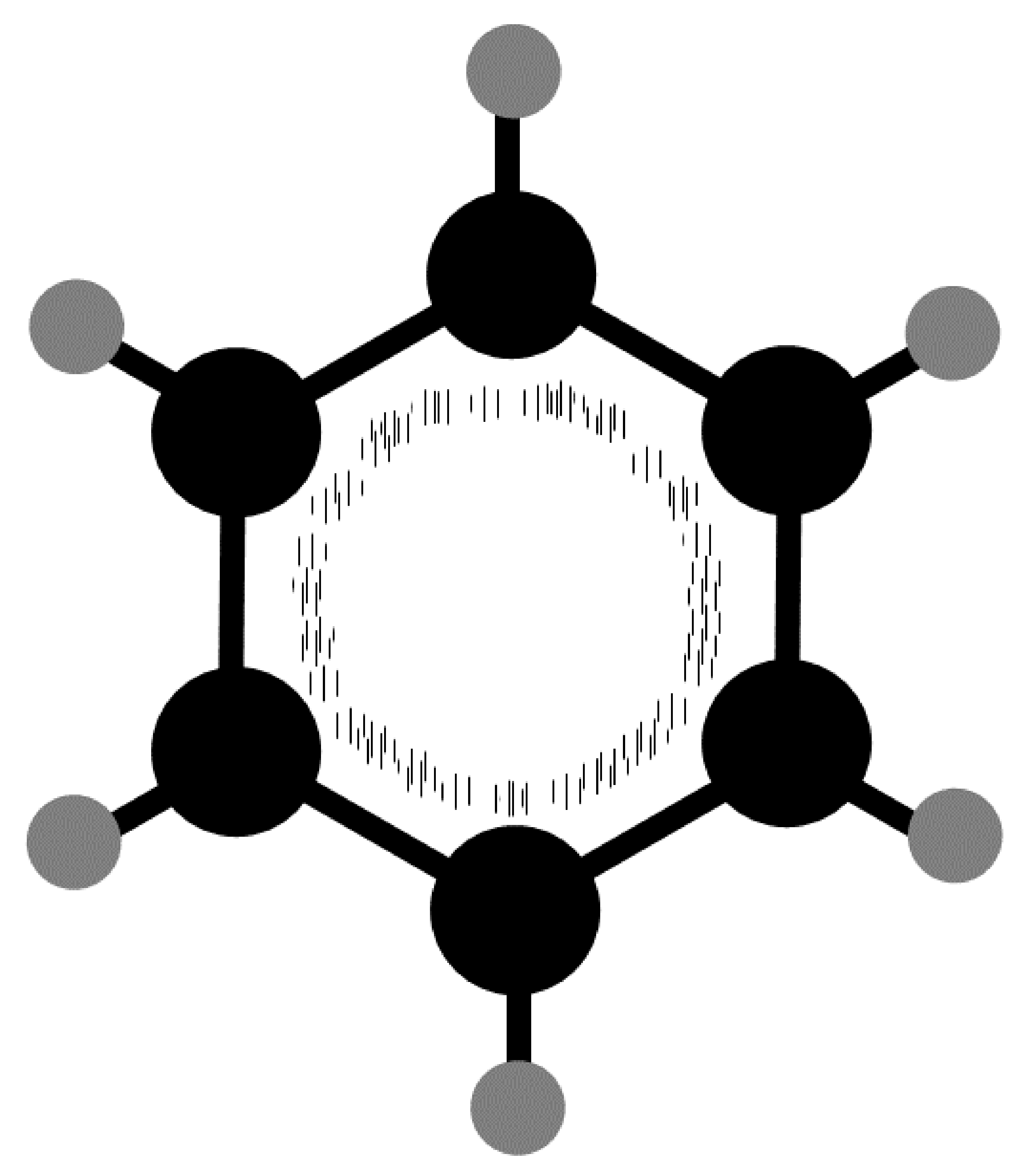

llustración: 


\section{Oxido-Reducción}

Si una especie recibe los electrones que otra le entrega, entonces estamos en presencia de una reacción química de oxido-reducción o redox. La especie que recibe se llama oxidante y la que los entrega, reductora. Un ejemplo de este tipo de reacción es la oxidación de un clavo en presencia de sulfato de cobre.

¿Veamos qué es lo que ocurre?

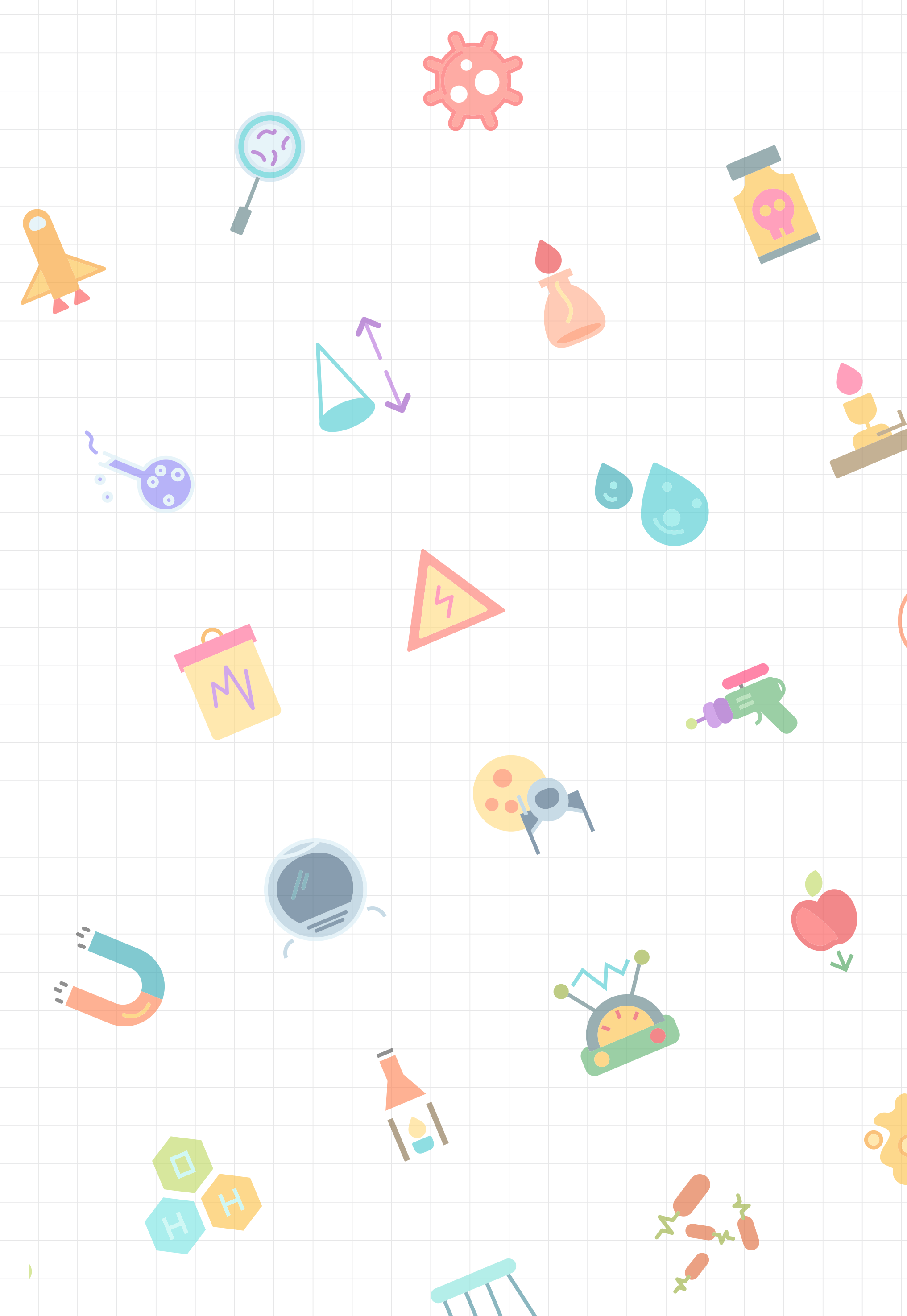




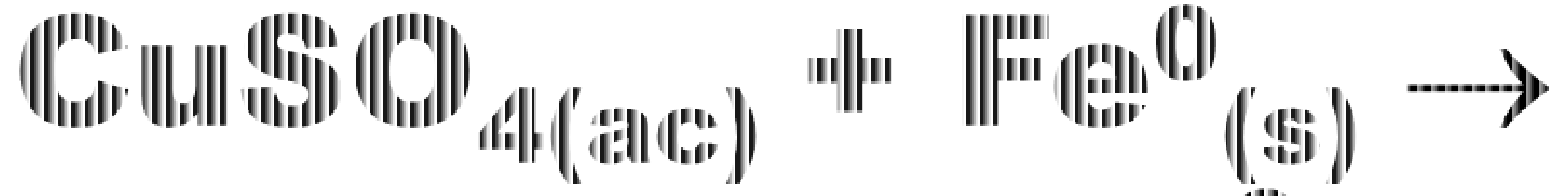

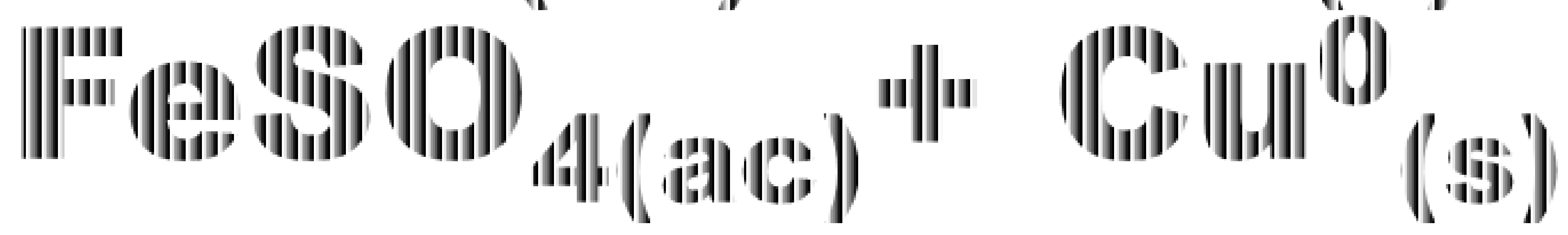
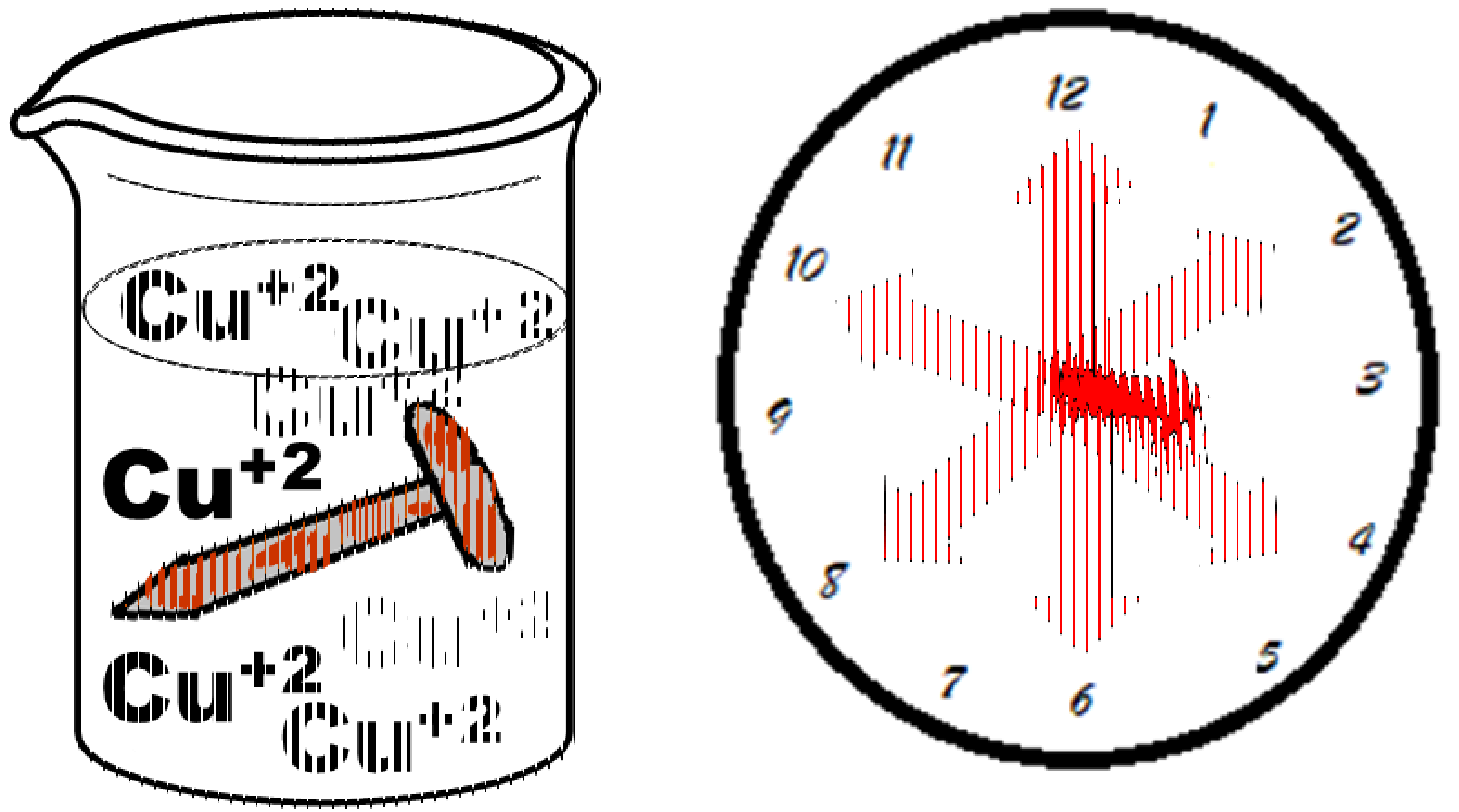


\section{Ataque antibacteriano}

Esta animación muestra la presencia de pequeñas moléculas llamadas péptidos, conformados por aminoácidos, estructuras básicas preparadas para combatir infecciones producidas por agentes patógenos.

Las bacterias son patógenos. Algunas de ellas poseen cargas negativas en su membrana, lo que permite que haya una atracción electroestática con los péptidos que posean cargas positivas. La interacción entre ambos causa la formación de un poro en la membrana y su consiguiente destrucción.

¿Puedes reconocer cuáles son las bacterias presentes en la animación? 


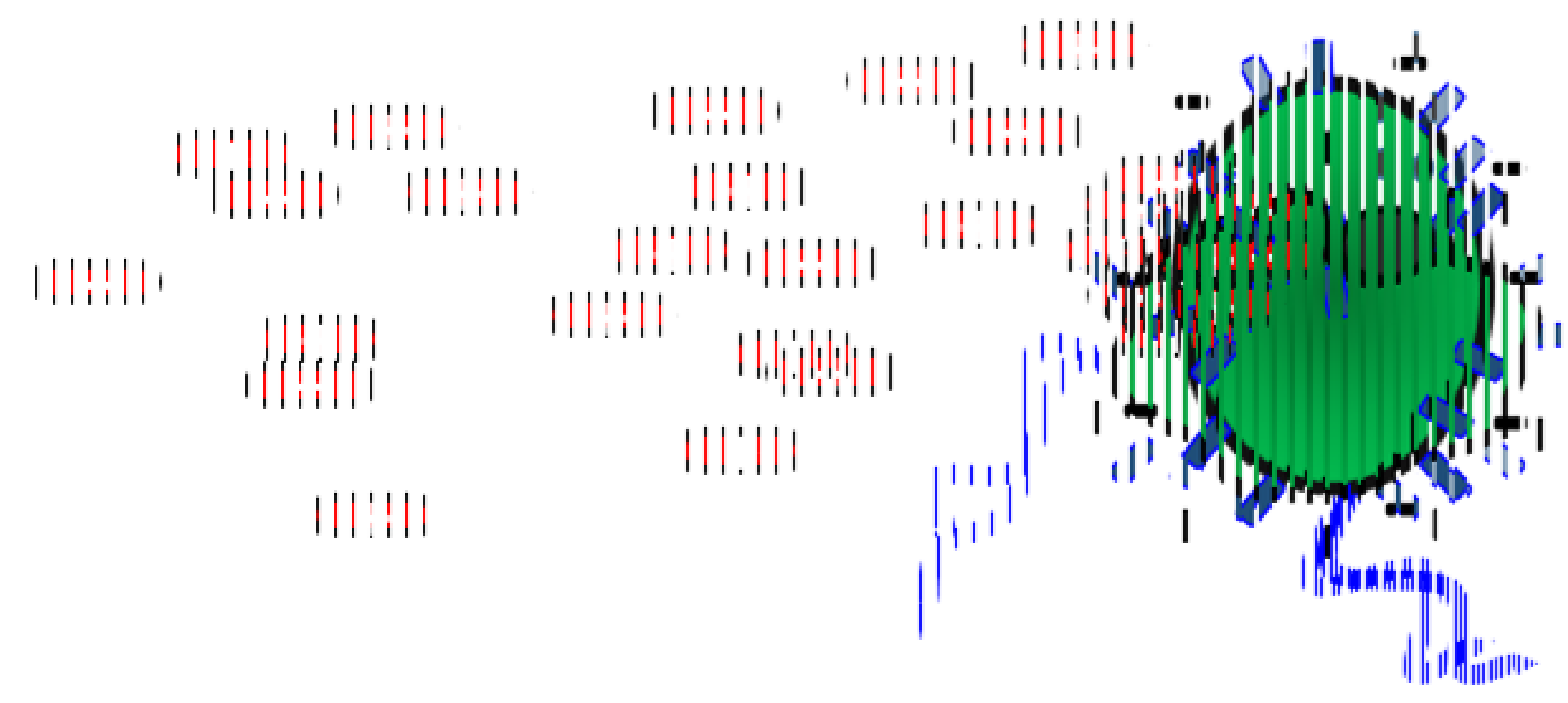

Ilustración: 


\section{Fagocitosis mediada poranticuerpos}

Esta animación muestra cómo las células plasmáticas derivadas de un linfocito $B$ activado y los macrófagos - ambas células de nuestro sistema inmunológico- nos defienden ante la presencia de agentes infecciosos. Si un patógeno (como las bacterias) ingresa a nuestro organismo, las células plasmáticas producen y secretan anticuerpos, que son proteinas que participan en el reconocimiento de moléculas presentes en la superficie de las bacterias. De esta forma, las bacterias son «marcadas» por los anticuerpos para que sean ingeridas y eliminadas por los macrófagos.

Esto se logra a través de los pseudópodos - «brazos» que poseen estos fagocitos- que permiten internalizar a las bacterias para su posterior destrucción en compartimentos llamados lisosomas.

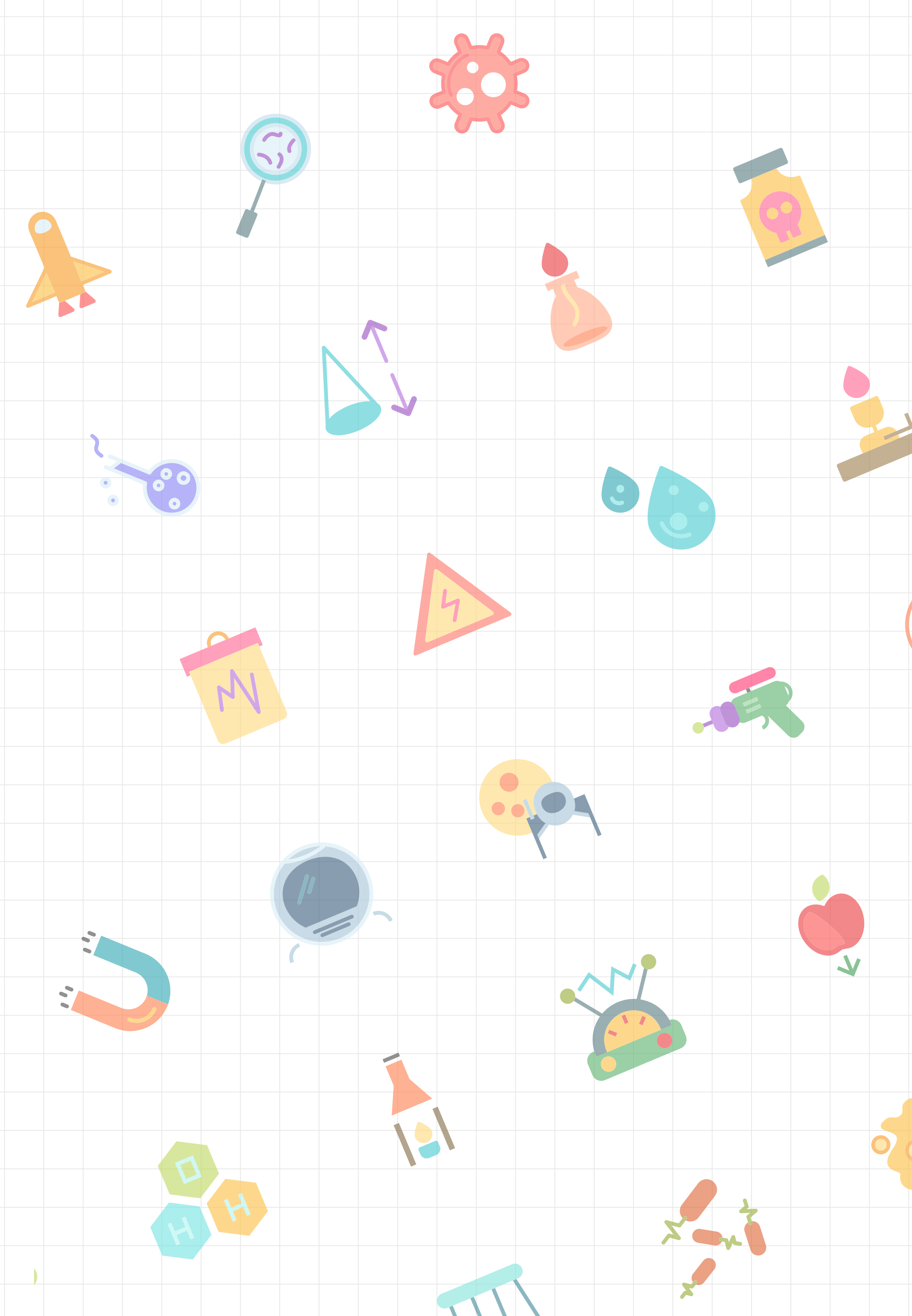




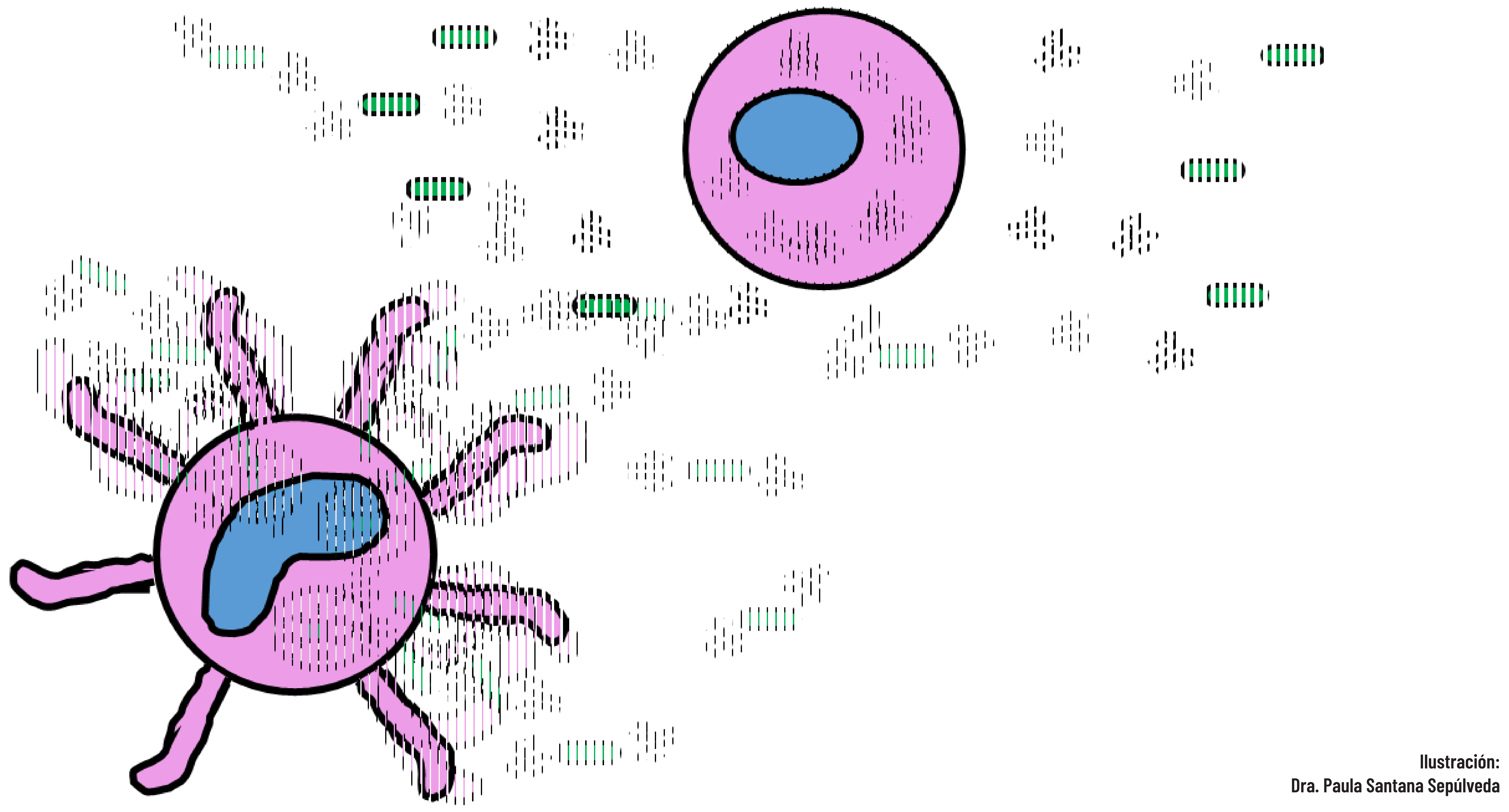




\section{Péndulo}

"La energía no se crea ni se destruye, solo se transfiere» es una de las posible formas de enunciar el principio de conservación de la energía.

En la figura podemos observar el típico péndulo de Newton, en el que se conserva la energía y la cantidad de movimiento lineal. Aquí, la primera esfera transfiere su momentum y energía justo en el instante que choca con su vecina, la que, a su vez, la traspasa a la última esfera que se eleva hasta la misma altura de lanzamiento de la primera esfera. Si consideráramos un sistema aislado, este proceso sería infinito, sin embargo, sabemos que en la realidad no lo es.

¿Se te ocurre alguna razón para explicar por qué el péndulo no oscila de manera infinita? 


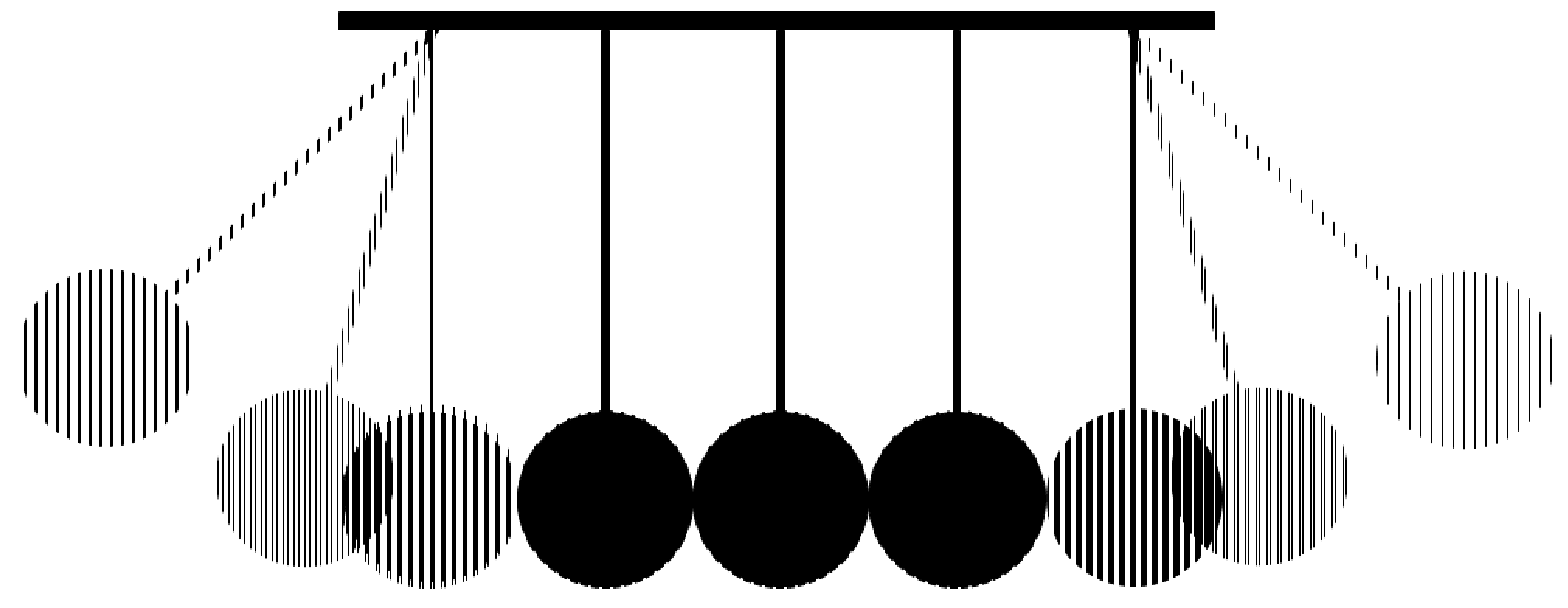




\section{Movimiento parabólico}

La cinemática es la unidad de la física que estudia el movimiento de los objetos sin importar la causa que los ocasiona.

En este caso, la figura a continuación muestra el movimiento parabólico -comúnmente conocido como lanzamiento de proyectil- donde un objeto, que es lanzado con un ángulo con respecto a la horizontal, describirá una trayectoria parabólica y su movimiento solo será influenciado por la fuerza de gravedad.

Además, en el cuerpo se puede observar que están descritos los vectores de velocidad, donde el único que cambia, en magnitud y sentido, es la componente vertical, típico de un movimiento uniforme acelerado, mientras que la componente horizontal se mantiene constante como el movimiento uniforme. ¿Conoces algún objeto que presente este tipo de comportamiento? 
$\mathbf{g}$
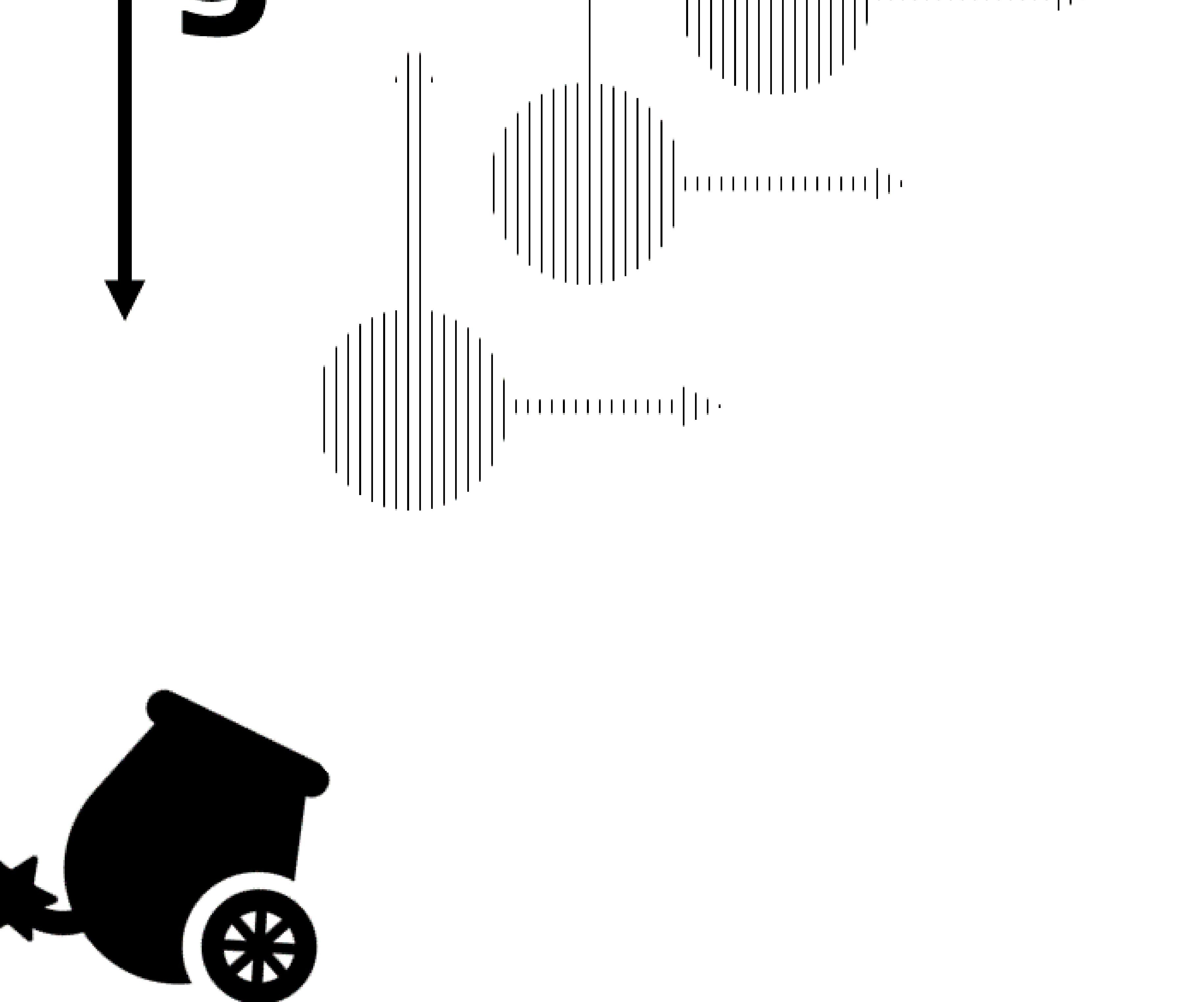

llustración: 


\section{Cambios de estado de la materia}

Si aplicamos calor a un trozo de hielo este se convertirá en líquido. A esta transformación se le conoce como fusión. Para el agua esto ocurre a $0^{\circ} \mathrm{C}$ y a 1 atmósfera de presión. Esto explica por qué el hielo se funde si no está dentro del congelador. Generalmente, afuera hay más que $0^{\circ} \mathrm{C}$ de temperatura.

Si al líquido que quedó le seguimos aplicando calor es probable que, al cabo de rato, no quede rastro de él ya que ahora todas las moléculas estarán en fase gaseosa. A este proceso se le denomina ebullición. Para el agua esto sucede a $100^{\circ} \mathrm{C}$ y a 1 atmósfera de presión.

Ambos procesos, eso sí, son reversibles ya que, si quisiéramos, podriamos traspasar todas las moléculas desde la fase gaseosa, a la líquida y luego a la sólida. ¿Por qué? Porque estas transformaciones son cambios físicos, es decir, no hay ruptura de enlaces químicos.

¿Cómo realizarías estos cambios en tu cocina?

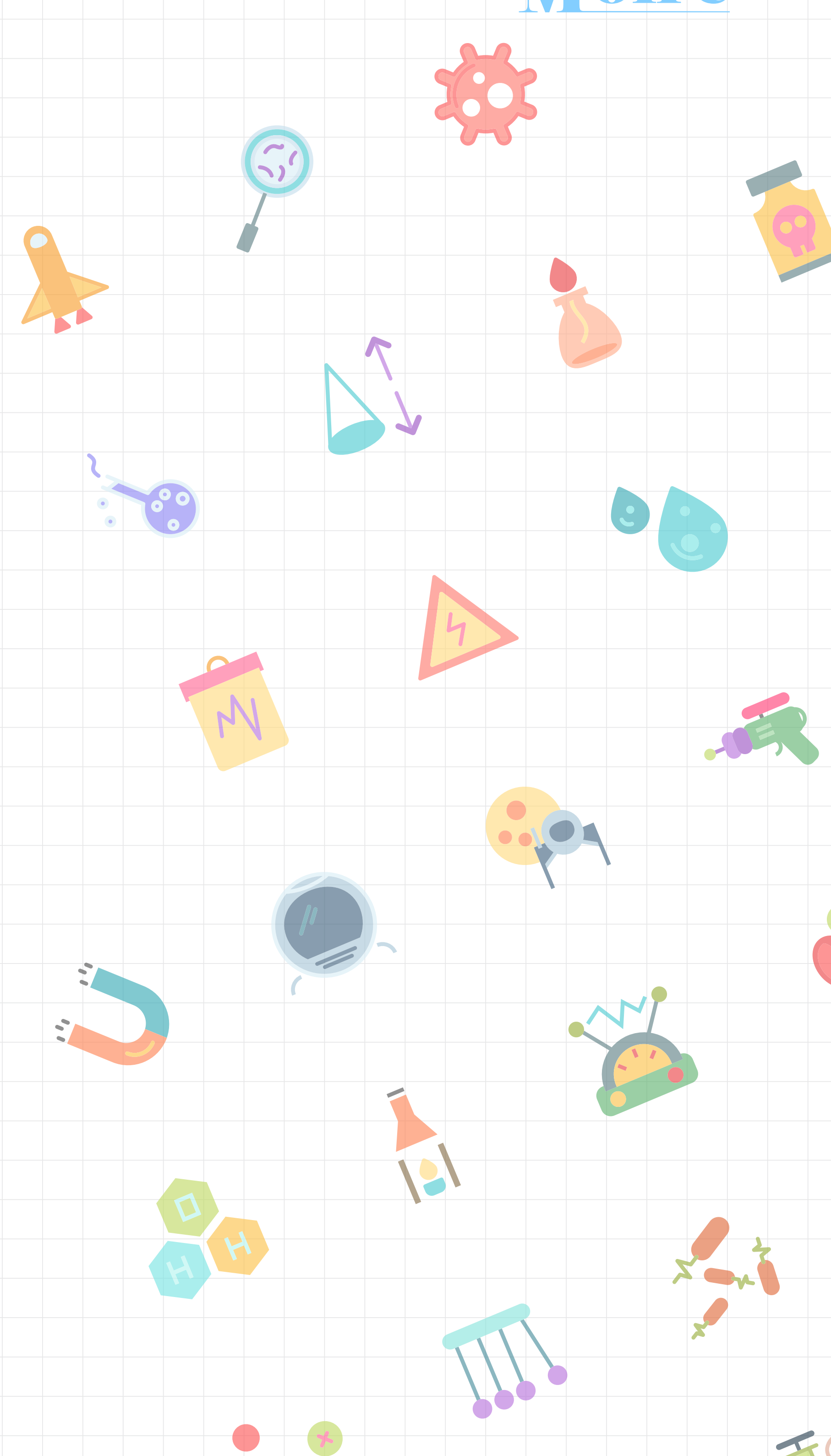




\section{Modos propios (partel)}

Todos los objetos pueden deformarse con mayor o menor dificultad dependiendo de su geometría y del material del que estén construidos. Piensa en una regla metálica, esta la podrías deformar, pero una barra de gruesa del mismo metal será imposible.

Sin embargo, existen formas que son más simples para deformar los objetos y que también dependen de su geometría y material. Pensemos de nuevo en la regla. Seguramente te será fácil doblarla en una dirección, pero estirarla o doblarla en otras direcciones puede ser muy complicado. Estos tipos de deformaciones que a los objetos «les gustan más» se denominan modos propios y se identifican por una frecuencia.

Las siguientes imágenes muestran los modos propios de una esfera (como una pelota chocando con el piso] y los de una placa metálica que vibra tras golpearla (como un martillo).

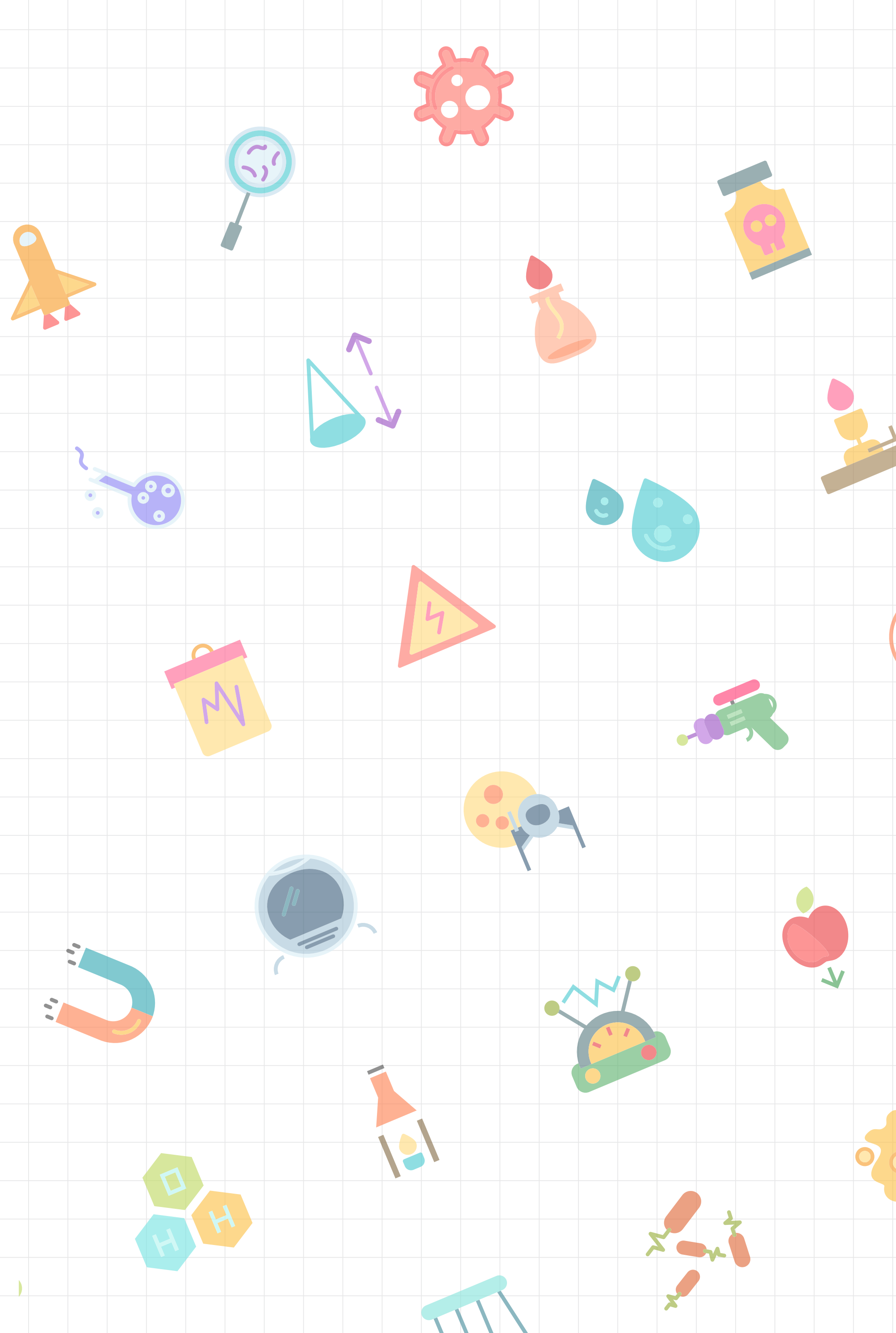



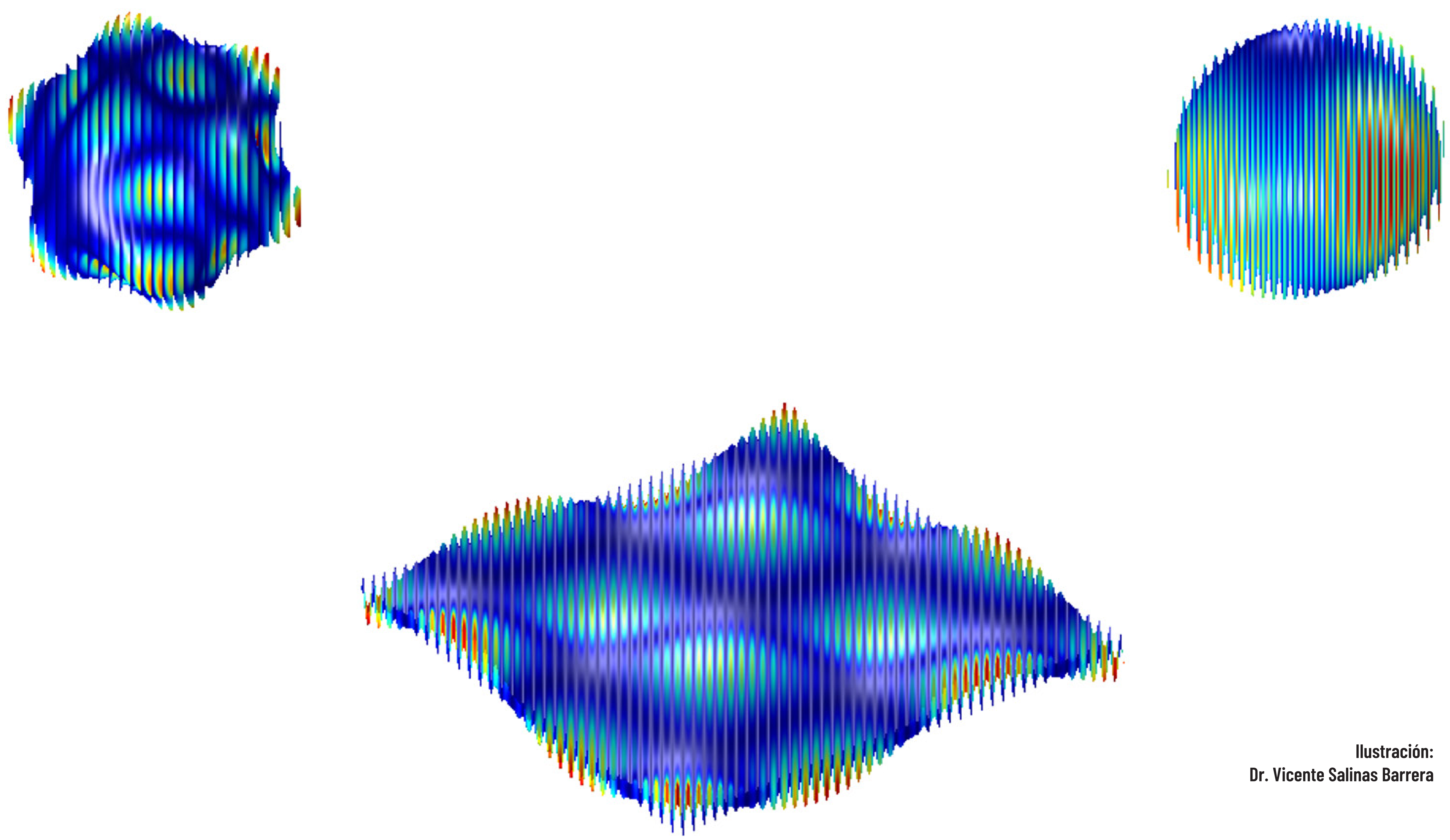

Ilustración: Dr. Vicente Salinas Barrera 


\section{Modos propios (parte II)}

Una de las aplicaciones más cotidianas donde se utilizan los modos propios es en los instrumentos musicales, tanto en los de aire, como en los de cuerda o percusión.

Al someter al instrumento a un esfuerzo, como un golpe al platillo o al diapasón, o al frotar la cuerda de un violín, el instrumento se moverá a la frecuencia (nota musical] que más le acomode en función del esfuerzo aplicado, excitándose así algún modo propio.

Las siguientes imágenes muestran tres instrumentos moviéndose en alguno de sus modos propios, lo que se traduce en la emisión de un sonido o nota musical (frecuencia).

¿Conoces algún otro instrumento musical que trabaje de esta manera? 


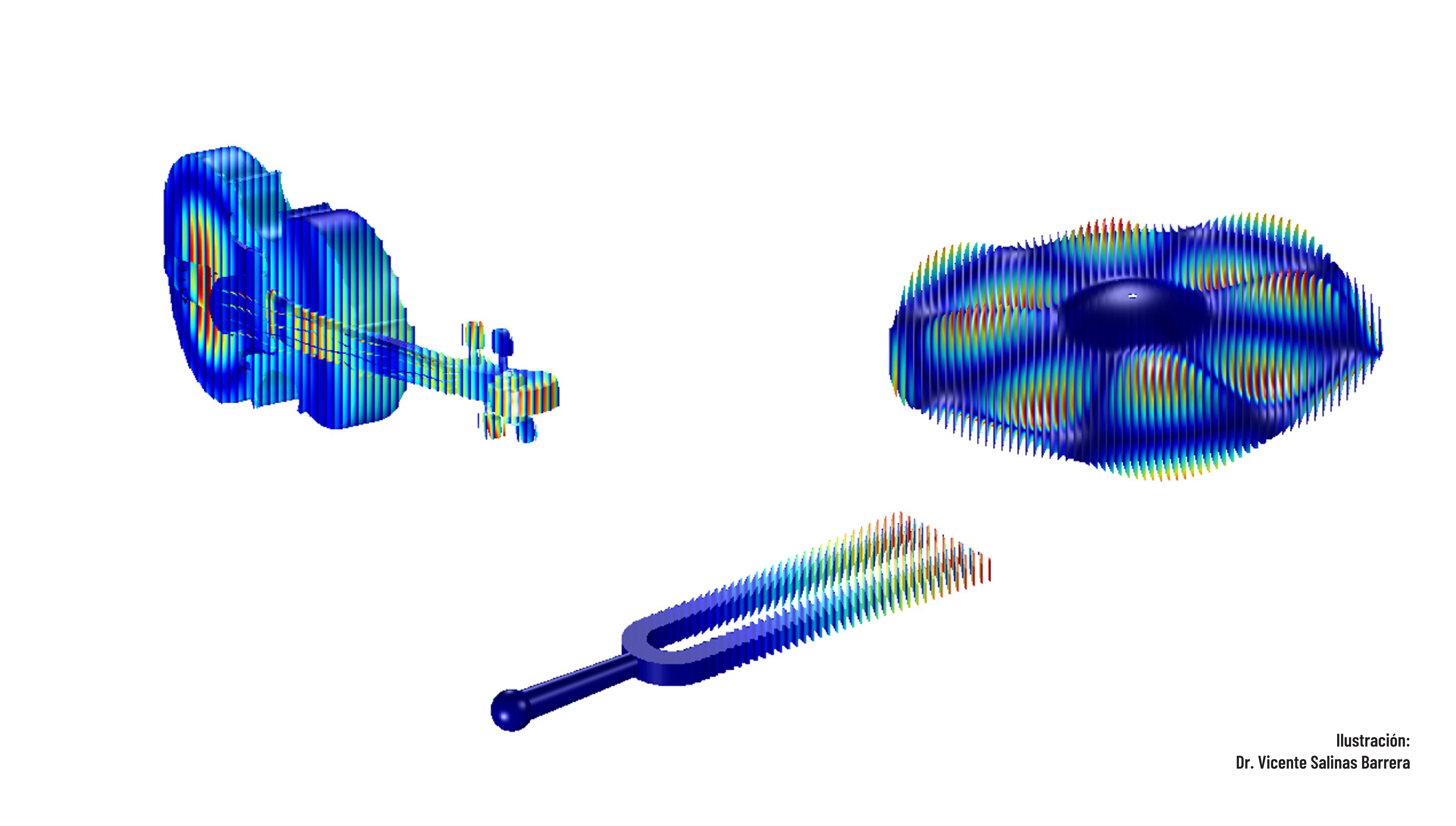




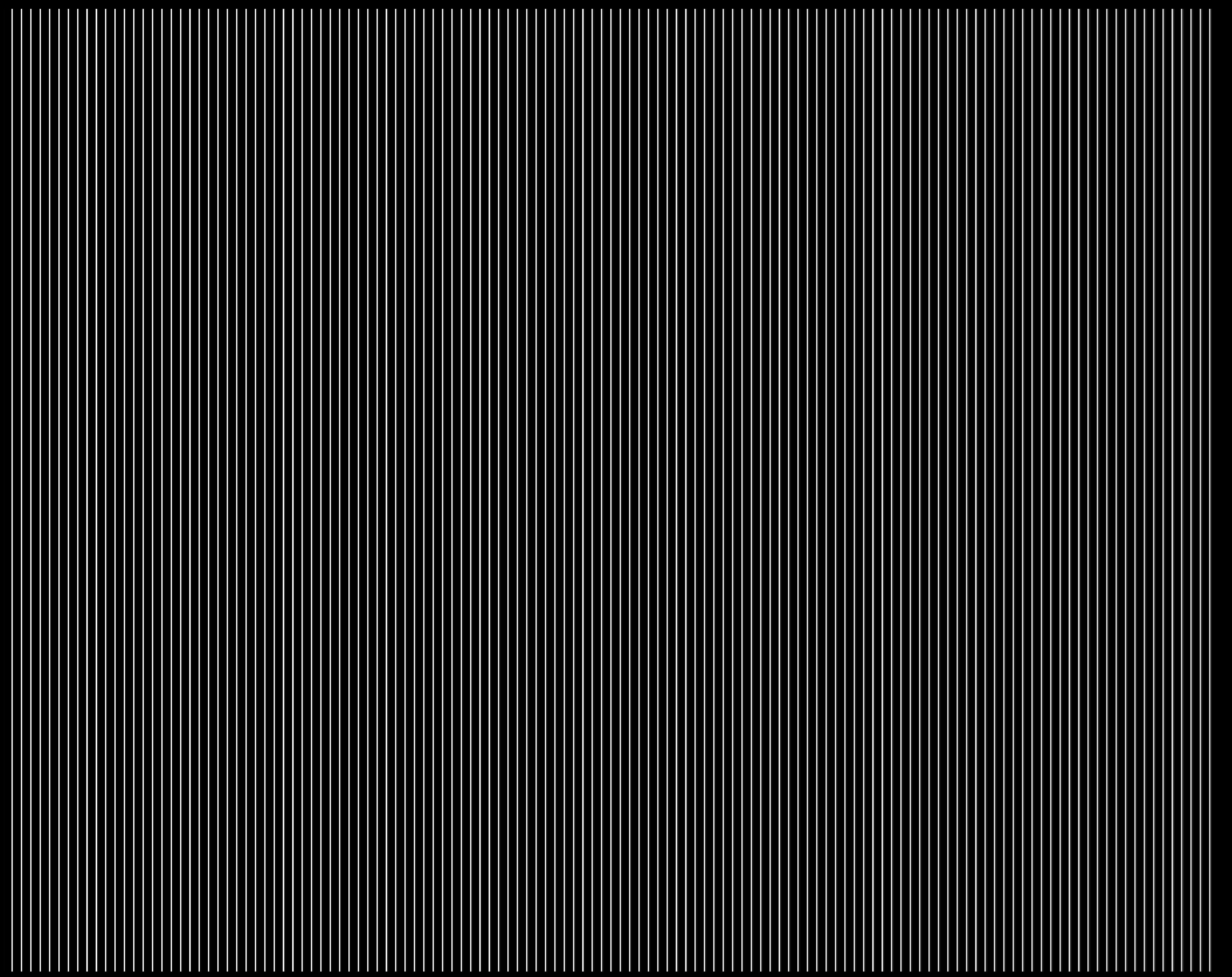




\section{El efecto Moiré}

Carolina Castillo Vicencio

Sebastián Michea Mora

Vicente Salinas Barrera

Paula Santana Sepúlveda

Cristián Tirapegui Calquín

Valeria Villalobos Lepe

\section{Primera edición: julio, 2020}

Santiago, Chile

Centro de Comunicación de las Ciencias http://ciencias.uautonoma.cl

(c) Universidad Autónoma de Chile

Avenida Pedro de Valdivia 425, Providencia

Santiago, Chile

Dirección editorial y corrección de textos: Isidora Sesnic Humeres

\section{Coordinación de contenido}

Jeannine Gaete Espina

Diseño y diagramación

Cristóbal Concha Mathiesen

ISBN: 978-956-8454-77-7

Registro de propiedad intelectual: 2020-A-5174

Este material puede ser copiado y redistribuido por cualquier medio o formato, además se puede remezclar, transformar y crear a partir del material siempre y cuando se reconozca adecuadamente la autoría y las contribuciones se difundan bajo la misma licencia del material original

\section{(c) (1) (2)}

